\section{Heat Treatment of Carbon under Various Pressures}

IT has been said that the degree of graphitization of carbon deponds chiefly on the highest temperature of heat treatment and that other conditions of heat treatment, such as holding time, are of secondary importanco. However, it was previously reported ${ }^{1}$ that the vacuum-evaporated carbon was scarcely graphitized in vacuum, although it was easily graphitizod undor atmospheric pressure. 'Therefore, we thought it necessary to study the effoct of the gas phase of heat treatment on the graphitization of carbon. In order to investigate this effect, a calcined petroleum coke was heat-treated under various pressures and its lattice constant $c_{0}$ was measured by means of X-ray diffraction method using extra-pure silicon powder as an inner standard.

The change of lattice constant $c_{0}$ with the temperature of heat treatment is represented in Fig. 1.

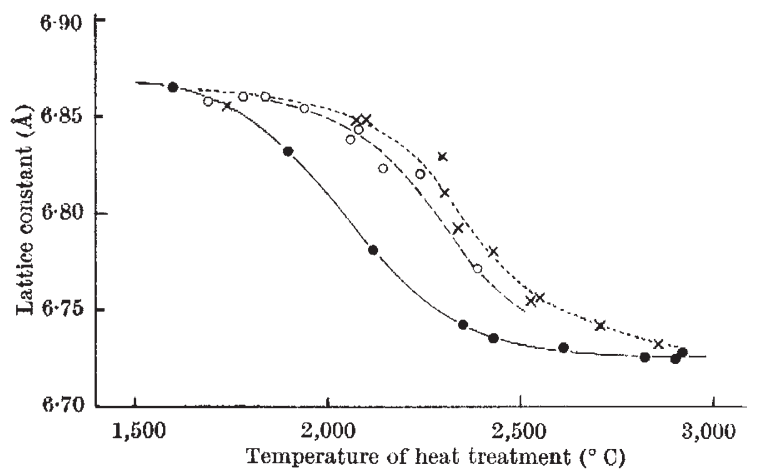

Fig. 1. Change of lattice constant, $c_{0}$, with temperature of heat treatment. 0 , under reduced pressure; $x$, in vacuum

Heat treatment under atmospheric prossure was made in a carbon granular resistance furnace of a type similar to an industrial graphitizing furnace. The details of this heat treatment were roported elsewhere ${ }^{2}$. Hoat treatment in vacuum of $10^{-2} \mathrm{~mm}$ mercury was made in a vacuum induction furnace. Heat treatment under reduced pressure $(7 \sim 8 \mathrm{~mm}$ mercury) was made in a bell-jar typo motallic chamber. In each case, the temperature of heat troatmont was directly measured with the aid of an optical pyromoter.

The results of this work indicate that the relation between the dogree of graphitization of carbon and the tomperature of heat treatment is strongly affected by the gas phaso of heat treatment. In this work, it was scarcely nocessary to consider the catalytic action of motallic impurities, because tho high-purity graphite (reactor grade) was used as a crucible. According to Mrozowski ${ }^{3}$, powdered coke was less graphitized than unpowdored. Therefore, the particle size distribution of the coke sample was controlled to the range of $\mathrm{I} .4 \sim 0.2 \mathrm{~mm}$ in order to eliminate the possiblo effect of particle size on the graphitization. Holding time at the highest temperature was about $15 \mathrm{~min}$ in each case. Heating-rate was about $200^{\circ} \mathrm{C} /$ min in tho hoat treatment both undor atmospheric pressuro and in vacuum, and about $2,000^{\circ} \mathrm{C} / \mathrm{min}$ in reduced pressure. But it was already reported that heating-rate has no effect on lattice constants of heattreated carbon 4 . Accordingly, it was not tho differonce of heating-rate that caused the difference in the behaviour of lattice constant shown in Fig. 1 .
The degree of graphitization of carbon therefore depends not only on the highest temperature but also on the gas phase of heat treatment, although it is not decisive whether the total pressure of gas phase or the partial pressure of any kind of existing gas, such as nitrogen or oxygen, has any effects on the graphitization.

\section{T. NODA}

M. INAGAKI

Department of Applied Chemistry, Nagoya University,

Furo-cho Chikusa-ku, Nagoya.

' Noda, T., and Matsuoka, H., J. Chem. Soc. Japan, Indust. Chem. Sec., 64, 2083 (1961).

${ }^{2}$ Inagaki, M., and Noda, T., Bull. Chem. Soc. Japan, 35, 1652 (1962). ${ }^{3}$ Mrozowski, S., Proc. First and Second Conf. on Carbon, 31 (Univ. of Buffalo, 1956).

${ }^{4}$ Okada, J., et al., Proc. Fifth Conf, on Carbon (in the press).

\section{Fractionation of Partially Isotactic Polypropylene Oxide}

WE have polymorized propylene oxide in dioxan with the zinc diothyl and water catalyst ${ }^{1}$, dissolved the resulting high-molecular-weight polymer in isooctane at $60^{\circ} \mathrm{C}$ and precipitated solid phases by lowering the temperature incrementally to $40^{\circ} \mathrm{C}$. In this way we were able to obtain several fractions which were identical in avorage molecular weight and in the distribution of molecular weights about the average. By further lowering of the temperature we obtained liquid-liquid phaso separation with fractionation occurring predominantly on the basis of molecular weight. A typical result of such a fractionation is shown in Fig. 1. Further analysis of that part of tho polymer undergoing liquid-liquid phase separation (some $80 \mathrm{wt} . \%$ ), coupled with cryoscopic measurements on the fraction of lowest molecular weight, indicates that the ratio of the weight- to the number-average molecular weight for the polymer is greator than 1,000 , the consequence of a large low molecular weight tail.

Other fractions produced in this way via solidliquid phase separation from iso-octane have been investigated in more detail. Table 1 records, for

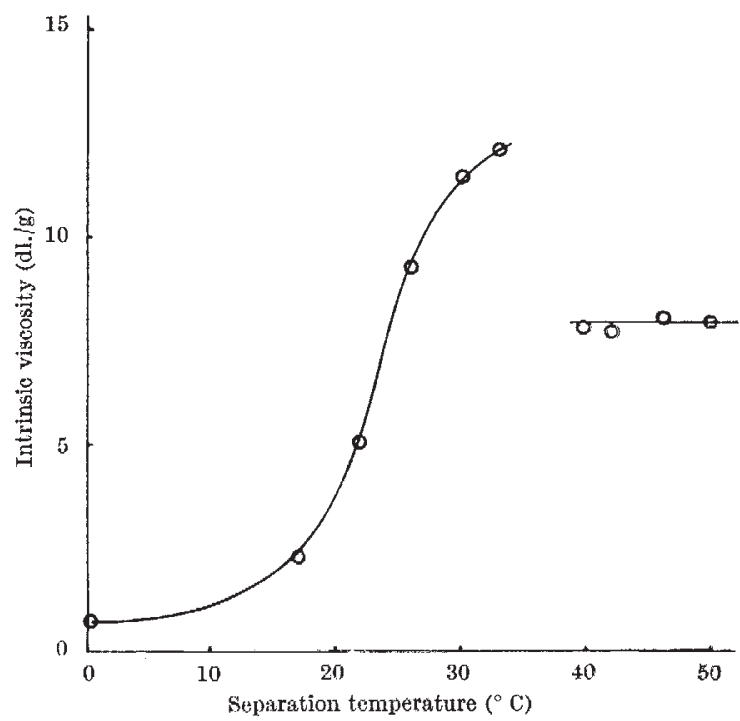

Fig. 1. The intrinsic viscosities (benzene at $25^{\circ} \mathrm{C}$.) of fractions of polypropylene oxide versus their temperature of separation 